\title{
Energy expenditure during heavy work and its interaction with body weight
}

\author{
BY P. HAGGARTY ${ }^{1}$, M. E. VALENCIA ${ }^{2}$, G. McNEILL ${ }^{1,3}$, N. L. GONZALES ${ }^{2}$, \\ S. Y. MOYA ${ }^{2}$, A. PINELLI ${ }^{2}$, L. QUIHUI ${ }^{2}$, M. S. SAUCEDO ${ }^{2}$, \\ J. ESPARZA ${ }^{2}$, J. ASHTON ${ }^{1}$, E. MILNE ${ }^{1}$ AND W. P. T. JAMES ${ }^{1}$ \\ ${ }^{1}$ Rowett Research Institute, Greenburn Rd, Bucksburn, Aberdeen AB21 9SB \\ ${ }^{2}$ CIAD AC, PO Box 1735, Hermosillo, Sonora, Mexico \\ ${ }^{3}$ Department of Medicine and Therapeutics, University of Aberdeen, Aberdeen AB9 $2 Z D$
}

(Received 9 October 1995 - Revised 8 July 1996 - Accepted 12 July 1996)

\begin{abstract}
The present study was designed to investigate the interaction between body weight and energy expenditure in well-nourished individuals. Energy expenditure was determined during a $10 \mathrm{~d}$ highly controlled work programme in apparently well-nourished adult male construction workers with a wide range of body weights (mean weight: 63.9 (SD 11.0, range 46.7-80.1) kg, mean BMI: 22.5 (SD 3.8, range 16.7-28.9) $\mathrm{kg} / \mathrm{m}^{2}$ ). Total energy expenditure (mean: 12.68 (SE 0.73) $\mathrm{MJ} / \mathrm{d}$ or 1.78 (SE 0.07) $\times$ BMR) was determined using doubly-labelled water and the energy costs of work activities by Oxylog. The energy expenditure during work (mean: 5.75 (SE 0.29) MJ/day or 3.48 (SE 0.09) $\times$ BMR) was estimated from the energy costs of individual tasks and the time spent in those tasks. The energy expenditure during discretionary time (mean: 4.37 (SE 0.58) MJ/d or 1.49 (SE 0.17) $\times$ BMR) was calculated by subtracting occupation and sleep expenditure (taken as $1 \times$ BMR) from total expenditure. Food intake and discretionary time allocation were recorded by the subjects. The energy expenditure in the programmed work activities (expressed as a multiple of BMR) showed a significant increase $(P=0.035)$ with increasing body weight, suggesting that the assumed constancy of BMR multiples across a wide range of body weights may not be valid. This assertion was supported by theoretical calculations based on empirically derived equations. In order to avoid errors which could be interpreted as metabolic 'adaptation' it may be necessary to take account of body weight when using the BMR-multiple approach to estimate energy requirements at low body weights.
\end{abstract}

Energy expenditure: Body weight: Physical activity: Doubly-labelled water

It has long been known that undernutrition leads to a reduction in the rate of metabolism (Benedict et al. 1919; Keys et al. 1950), a phenomenon which has given rise to the concept of 'adaptation'. The practical importance of this issue stems from the fact that estimates of energy requirements such as those described by the Food and Agriculture Organization/World Health Organization/United Nations University (FAO/WHO/UNU) (1985) are used to determine the food needs of populations but the phenomenon of 'adaptation' would bring into question the universal applicability of these estimates. Despite the potential importance of this issue it has proved difficult to establish the reality or otherwise of metabolic 'adaptation' mainly because energy expenditure is largely determined by the body weight, and therefore differences in body weight between well-nourished and chronically undernourished individuals may obscure any effect of chronic undernutrition on metabolism. During chronic energy deficiency the tissue mass of the body falls until the 
mass of tissue and level of expenditure can be sustained by the level of intake. As a direct consequence of the fall in body weight, the BMR and the energy costs of activities are reduced. However, as James (1988) has pointed out, 'a change in energy expenditure which simply reflects the outcome of a change in body weight and in the mass of metabolically active tissue cannot be considered a true adaptation'. True 'adaptation' may have two components; a reduction in physical activity and an increase in energetic efficiency beyond that which would be predicted from the change in tissue mass alone. Shetty \& James (1994) have argued that there is sufficient evidence to support behavioural 'adaptation' but in order to establish the baseline beyond which evidence for metabolic or non-behavioural 'adaptation' may be found, it is necessary to define the relationship between body weight and expenditure in well-nourished individuals. That is the aim of the present study.

In an attempt to distinguish between the direct effects of chronic undernutrition on metabolism and behaviour and the indirect effects acting via the concomitant changes in body weight this study was carried out in subjects with a wide range of body weights but with the means to purchase food of sufficient quantity and quality to meet their nutritional requirements. Specifically, this study set out to address the following questions in apparently well-nourished subjects: (1) what is the relationship between energetic efficiency and body weight?; (2) do individuals with low body weight and 'heavy' occupations compensate by expending less energy during discretionary time?; (3) how do measurements of expenditure in subjects performing 'heavy' work compare with estimates in the FAO/WHO/UNU (1985) and Department of Health (1991) reports? These questions were addressed by measuring total energy expenditure (with doubly-labelled water) and expenditure during occupation (using a portable $\mathrm{O}_{2}$ analyser) in adult male subjects accustomed to 'heavy' physical work. During the study period subjects performed a highly defined and controlled work programme designed to simulate, as closely as possible, their typical work activities. The time spent in discretionary activity and sleep was determined using activity diaries and the energy expended during discretionary activity was calculated by subtracting occupation and sleep expenditure from total energy expenditure.

\section{MATERIALS AND METHODS}

\section{Subjects}

Thirteen adult male construction workers (age 18-30 years; weight $46 \cdot 7-80 \cdot 1 \mathrm{~kg}$; BMI $16.7-28.9 \mathrm{~kg} / \mathrm{m}^{2}$ ) from the city of Hermosillo, Sonora, Mexico were recruited for this study. All subjects underwent a medical examination to assess suitability for the study and all gave informed written consent to take part. The study protocol was approved by CIAD's ethical committee.

\section{Food intake}

Each subject, together with the person in the household who usually prepared the meals, was instructed in the method of recording the food intake. Weighed food intake was carried out for the $10 \mathrm{~d}$ of the study. Two sets of portable dietary scales were provided for each subject, one to be kept at home and the other for use outside the home. The food records were monitored and coded daily and, if necessary, the household was visited to clarify any ambiguities in the records. The analysis of the composition of the ingested food was carried out using a computer program developed at Centro de Investigación en Alimentacion y Dessarollo AC (CIAD) using several food composition databases: Hernandez et al. (1980); 
U.S. Department of Agriculture (1986); Paul \& Southgate (1985), and direct analysis of foods specific to the region of Northern Mexico where the study was carried out (Jardines et al. 1985; Grijalva et al. 1995).

\section{Activity programme}

During the $10 \mathrm{~d}$ of the study subjects undertook $8 \mathrm{~d}$ of a highly controlled and defined work programme designed to mimic as closely as possible their typical work activities. Each working day lasted $8 \mathrm{~h}$ with a $1 \mathrm{~h}$ break for lunch. In each hour of work the subjects undertook three prescribed activities for $15 \mathrm{~min}$ each, followed by a $15 \mathrm{~min}$ rest period. The three activities were: (a) walking on a treadmill at $3.1 \mathrm{~km} / \mathrm{h}$ and zero slope, (b) walking in time to a metronome at $110 \mathrm{steps} / \mathrm{min}$, and (c) building a wall of $3.06 \mathrm{~m}^{2}$ with cement blocks $(150 \times 100 \times 400 \mathrm{~mm})$ each weighing $7.4 \mathrm{~kg}$. All activities were performed under continuous supervision. Each subject also kept an activity diary during the $10 \mathrm{~d}$ study period and this was used to estimate the time spent in discretionary activity and sleep.

\section{Measurement of the BMR}

BMR was determined in subjects after an overnight stay in a metabolic unit. The day before the measurement an evening meal was provided at one third the estimated energy requirement (from FAO/WHO/UNU, 1985). BMR was determined by ventilated hood indirect calorimetry using a Deltatrac metabolic monitor (Datex Intr., Helsinki, Finland). The Deltatrac was calibrated before each run with a span gas mixture of $\mathrm{O}_{2}-\mathrm{CO}_{2}$ $(95.94: 4 \cdot 06, \mathrm{v} / \mathrm{v})$ previously verified by Haldane analysis. Atmospheric pressure was set according to a $\mathrm{Hg}$ barometer (Princo, PA, USA). The Deltatrac system was regularly checked by measuring the gas recovery during propane gas burns at a rate within the range of the energy expenditure measurements in the subjects; calibration gas burns for the Deltatrac were in the range 5.4-10.2 MJ/d and the percentage recoveries were 99.69 and 98.7\% for $\mathrm{O}_{2}$ and $\mathrm{CO}_{2}$ respectively; the measured RQ was 0.598. During BMR measurements the room was maintained at $25^{\circ}$ and $45-60 \%$ relative humidity.

\section{The energy cost of programmed activities}

The energy expenditure during programmed activities was determined using the Oxylog portable $\mathrm{O}_{2}$ consumption meter (P.K. Morgan, Kent) (Humphrey \& Wolf, 1977; McNeill et al. 1987). The straps were modified to enable the Oxylog to be worn on the back to withstand the movements, such as leaning forward as in wall construction, that subjects were required to perform. The Oxylog was calibrated against a ventilated hood system as described by Haggarty et al. (1994b).

\section{Doubly-labelled water}

A venous blood sample of $20 \mathrm{ml}$ was taken immediately after the BMR measurement, and whilst subjects were still fasted, for determination of the pre-dose ${ }^{2} \mathrm{H}$ and ${ }^{18} \mathrm{O}$ abundance. Subjects then drank doubly-labelled water (DLW; $0.19 \mathrm{~g} \mathrm{H}_{2}{ }^{18} \mathrm{O}$ and $0.24 \mathrm{~g}^{2} \mathrm{H}_{2} \mathrm{O} / \mathrm{kg}$ body weight) and a second venous blood sample was taken $3 \mathrm{~h}$ later. A portion of urine was obtained from the second voiding of the day on each day of the study. All samples were analysed for ${ }^{18} \mathrm{O}$ and ${ }^{2} \mathrm{H}$ and the curve fitting was carried out as described elsewhere 
(Haggarty et al. 1994a). The ${ }^{2} \mathrm{H}:{ }^{18} \mathrm{O}$ pool sizes ratio was 1.047 (SD 0.013). Fat free mass (FFM) was calculated from the $\mathrm{H}_{2}{ }^{18} \mathrm{O}$ dilution space assuming that body water $=\mathrm{H}_{2}{ }^{18} \mathrm{O}$ space $/ 1.01$, that $F F M=0.732 \times$ body water and body fat =body weight - FFM. Fractionated water loss was calculated as the mid-point of a maximum physiological range (Haggarty et al. 1994a,b). The minimum fractionated water loss was estimated using only breath water loss and the maximum as the breath water loss plus the resting transcutaneous water loss. The value used in calculations was the mid-point of the two values and the range was incorporated into the assessment of the overall precision of energy expenditure (Haggarty et al. 1994a). This approach ensures that the DLW-derived expenditure values are accurate to within the given estimates of precision. The mean proportion of water loss which was fractionated was estimated by this method at 0.18 (SD 0.02 ). The RQ was taken to be equivalent to the food quotient (FQ) which was calculated from the composition of the recorded intake. Energy expenditure was calculated from $\mathrm{CO}_{2}$ production (litres/d) and RQ using the following rearrangement of the Weir (1949) equation:

$$
\text { expenditure }(\mathrm{MJ} / \mathrm{d})=4.598 \times \mathrm{CO}_{2}+16.302\left(\mathrm{CO}_{2} / \mathrm{RQ}\right)
$$

\section{Statistics}

Group means are given with the standard deviation (SD) or standard error (SE). Statistical analysis was carried out using Minitab (Minitab Inc., Philadelphia, USA). The associations between the variables of interest and the body weight were assessed using Spearman's rank correlation. Although the associations of these variables with the BMI are not presented, the level of correlation between the body weight and BMI ( $r$ 0.958) means that the same general pattern can also be assumed for correlations with BMI. The significance of the difference between the measured BMR and that predicted by FAO/WHO/UNU (1985) was determined by paired $t$ test.

\section{RESULTS}

The subjects studied (Table 1) were all construction workers accustomed to hard physical work. Subjects were selected to represent the range of body weights (mean: 63.9 (SD 11.0, range 46.7-80.1) kg) and BMI (mean: 22.5 (SD 3.8, range 16.7-28.9) $\mathrm{kg} / \mathrm{m}^{2}$ ) found in this population. The mean FFM was 52.2 (SD 6.6, range 40.6-61.4) $\mathrm{kg}$ and body fat 17.8 (SD 6.4 , range $9.5-29.7) \%$. Neither the height nor the age was significantly correlated with body weight, but, as anticipated, there were significant increases in the BMI, percentage body fat and FFM with increasing body weight (Table 1).

The diet consumed by these workers (Table 2) was typical of the region, consisting mainly of beans and flour tortillas. The energy content of the recorded food intake was 12.7 (SE 0.67$) \mathrm{MJ} / \mathrm{d}$. The fat content of the diet (38\% of energy) was very similar to that found in the UK and this is reflected in the FQ $(0.855)$ which again is close to that typically found in the UK (Black et al. 1986). The intakes of the other macronutrients, also expressed as a percentage of energy, were 13.1 (SE 1)\% for protein, 46 (SE 2)\% for carbohydrate and 4 (SE $1) \%$ for alcohol. There was no significant association between any of these variables and body weight.

Table 3 shows the average daily time spent in the three main categories of work, sleep and discretionary activities over the $10 \mathrm{~d}$ experimental period. On weekdays subjects performed a highly standardized and controlled work protocol for $7 \mathrm{~h} / \mathrm{d}$ with a $1 \mathrm{~h}$ rest for 
Table 1. Physical characteristics of subjects

\begin{tabular}{|c|c|c|c|c|c|c|}
\hline Subjects & $\begin{array}{c}\text { Age } \\
\text { (years) }\end{array}$ & $\begin{array}{c}\text { Weight } \\
\text { (kg) }\end{array}$ & $\begin{array}{l}\text { Height } \\
\text { (m) }\end{array}$ & $\underset{\left(\mathrm{kg} / \mathrm{m}^{2}\right)}{\mathrm{BMI}}$ & $\begin{array}{c}\text { Body fat } \\
(\%)^{*}\end{array}$ & $\begin{array}{l}\text { FFM } \\
(\mathrm{kg})^{*}\end{array}$ \\
\hline 1 & 28 & 48.8 & 1.71 & 16.7 & 9.5 & $44 \cdot 2$ \\
\hline 2 & 20 & $46 \cdot 7$ & 1.58 & 18.6 & $13 \cdot 1$ & 40.6 \\
\hline 3 & 20 & 54.9 & 1.68 & 19.4 & $14 \cdot 6$ & 46.9 \\
\hline 4 & 21 & 55.4 & 1.68 & 19.7 & 11.9 & $48 \cdot 8$ \\
\hline 5 & 19 & $60 \cdot 6$ & 1.69 & 21.2 & $12 \cdot 8$ & 52.8 \\
\hline 6 & 20 & $58 \cdot 0$ & 1.69 & 20.4 & 17.6 & 49.9 \\
\hline 7 & 24 & $62 \cdot 5$ & $1 \cdot 70$ & 21.6 & $21 \cdot 2$ & 49.3 \\
\hline 8 & 20 & 70.8 & 1.78 & 22.3 & 13.3 & 61.4 \\
\hline 9 & 20 & 67.4 & 1.70 & $23 \cdot 1$ & $14 \cdot 2$ & 57.3 \\
\hline 10 & 25 & $76 \cdot 8$ & 1.70 & 26.6 & 21.0 & $60 \cdot 7$ \\
\hline 11 & 20 & $71 \cdot 9$ & 1.64 & 26.7 & 29.7 & 50.5 \\
\hline 12 & 18 & 77.0 & 1.68 & 27.2 & 27.6 & 55.7 \\
\hline 13 & 18 & $80 \cdot 1$ & 1.66 & 28.9 & 24.5 & $60 \cdot 4$ \\
\hline Mean & 21 & 63.9 & 1.68 & 22.5 & 17.8 & 52.2 \\
\hline SD & 2.9 & 11.0 & 0.04 & 3.8 & 6.4 & 6.6 \\
\hline \multicolumn{7}{|c|}{ Correlation with body weight } \\
\hline$r$ & -0.420 & - & 0.008 & 0.984 & 0.742 & 0.857 \\
\hline$P$ & 0.153 & - & 0.978 & $<0.001$ & 0.004 & $<0.001$ \\
\hline
\end{tabular}

FFM, fat-free mass.

${ }^{*}$ Body water $=\mathrm{H}_{2}{ }^{18} \mathrm{O}$ space $/ 1.01 ; \mathrm{FFM}=0.732 \times$ body water.

Table 2. Composition of diet in a $10 \mathrm{~d}$ period by weighed intake

\begin{tabular}{lcccccc}
\hline Subject & $\begin{array}{c}\text { Energy } \\
(\mathrm{MJ} / \mathrm{d})\end{array}$ & $\begin{array}{c}\text { Protein } \\
(\% \mathrm{E})\end{array}$ & $\begin{array}{c}\text { Fat } \\
(\% \mathrm{E})\end{array}$ & $\begin{array}{c}\text { CHO } \\
(\% \mathrm{E})\end{array}$ & $\begin{array}{c}\text { Alcohol } \\
(\% \mathrm{E})\end{array}$ & FQ \\
\hline 1 & 13.07 & 17 & 43 & 41 & 0 & 0.845 \\
2 & 10.87 & 17 & 47 & 36 & 0 & 0.832 \\
3 & 11.77 & 12 & 33 & 47 & 8 & 0.856 \\
4 & 14.86 & 13 & 36 & 45 & 7 & 0.850 \\
5 & 11.86 & 11 & 49 & 49 & 0 & 0.863 \\
6 & 12.24 & 14 & 30 & 50 & 7 & 0.866 \\
7 & 11.41 & 17 & 45 & 37 & 0 & 0.836 \\
8 & 16.67 & 13 & 27 & 58 & 2 & 0.889 \\
9 & 9.81 & 13 & 43 & 44 & 0 & 0.850 \\
10 & 11.36 & 11 & 37 & 43 & 9 & 0.843 \\
11 & 11.01 & 10 & 34 & 48 & 8 & 0.855 \\
12 & 15.99 & 11 & 33 & 56 & 0 & 0.884 \\
13 & 14.24 & 12 & 32 & 46 & 9 & 0.852 \\
Mean & 12.70 & 13 & 38 & 46 & 4 & 0.855 \\
SE & 0.67 & 1 & 2 & 2 & 1 & 0.005 \\
& & -0.638 & -0.405 & 0.401 & 0.377 & 0.325 \\
$r$ & 0.192 & 0.019 & 0.170 & 0.174 & 0.204 & 0.279 \\
$P$ & 0.529 & Correlation with body weight & & & \\
\hline
\end{tabular}

$\mathrm{FQ}$, food quotient; $\mathrm{CHO}$, carbohydrate, \% $\mathrm{E}$, percentage of total energy intake.

lunch. After taking account of the two weekend days covered by the study, the average time spent in occupation over the $10 \mathrm{~d}$ DLW period was $5.6 \mathrm{~h} / \mathrm{d}$. The value for subject 2 was $5.5 \mathrm{~h} / \mathrm{d}$ because one part of a working day was missed but this had little effect on the overall mean of the group. There was no significant association between body weight and the hours spent in sleep (mean of 8.7 (SE 0.3 ) h/d) or discretionary activities (mean of 9.8 (SE 0.3) h/d). 
Table 3. Allocation of time to sleep, occupational and discretionary activities

\begin{tabular}{cccc}
\hline \hline Subject & $\begin{array}{c}\text { Sleep } \\
(\mathrm{h} / \mathrm{d})\end{array}$ & $\begin{array}{c}\text { Occupation } \\
(\mathrm{h} / \mathrm{d})\end{array}$ & $\begin{array}{c}\text { Discretionary } \\
(\mathrm{h} / \mathrm{d})\end{array}$ \\
\hline 1 & 10.2 & 5.6 & 8.2 \\
2 & 8.7 & 5.2 & 10.1 \\
3 & 8.3 & 5.6 & 10.1 \\
4 & 8.2 & 5.6 & 10.2 \\
5 & 9.1 & 5.6 & 9.3 \\
6 & 8.5 & 5.6 & 9.9 \\
7 & 10 & 5.6 & 8.4 \\
8 & 7.4 & 5.6 & 11.0 \\
9 & 8.4 & 5.6 & 10.0 \\
10 & 8.5 & 5.6 & 8.9 \\
11 & 9.9 & 5.6 & 11.5 \\
12 & 6.9 & 5.6 & 9.7 \\
13 & 8.7 & 5.6 & 9.8 \\
Mean & 8.7 & 5.6 & 0.3 \\
SE & 0.3 & 0.0 & 0.066 \\
& Correlation with body weight & 0.463 & 0.830 \\
\hline
\end{tabular}

Within each hour of work, subjects carried out three highly controlled activities for 15 min on each activity: activity 1 , walking at 112 steps/min; activity 2 , walking on a treadmill at $5.6 \mathrm{~km} / \mathrm{h}$; activity 3 , wall construction using $7.4 \mathrm{~kg}$ concrete blocks, followed by $15 \mathrm{~min}$ rest. The measured energy costs of these activities were $20 \cdot 17$ (SE $1 \cdot 12$ ) $\mathrm{kJ} / \mathrm{min}$ for activity $1,20.94$ (SE 1.08) kJ/min for activity 2 and 21.6 (SE 1.23) kJ/min for activity 3 . Predictably, the absolute level of expenditure $(\mathrm{kJ} / \mathrm{min})$ increased with increasing body weight for each type of activity (activity $1, r 0.802, P=0.001$; activity $2, r 0.874$, $P<0.001$; activity $3, r 0.857, P<0.001)$. When expressed per $\mathrm{kg}$ body weight the mean energy costs were 0.318 (SE 0.013 ) $\mathrm{kJ} / \mathrm{kg}$ per min for activity $1,0.329$ (SE 0.008$) \mathrm{kJ} / \mathrm{kg}$ per min for activity 2 and 0.340 (SE 0.013 ) $\mathrm{kJ} / \mathrm{kg}$ per min for activity 3 . As a multiple of the measured BMR the mean energy costs were 4.08 (SE 0.16) $\times$ BMR for activity 1, 4.25 (SE 0.16 ) $\times$ BMR for activity 2 and 4.37 (SE 0.16) $\times$ BMR for activity 3 . Although there was no significant change with body weight for any of the three activities, it can be seen from Fig. 1 that there was a trend toward increasing BMR multiple with increasing body weight for each of the three activities. One of the main functions of the BMR multiple approach is to correct energy expenditure for differences in body weight, yet it would appear from comparison of the gradients of the regression lines that, for the three activities studied here, the older approach of expressing expenditure per $\mathrm{kg}$ body weight (average gradient $-0 \cdot 30$ ) is, if anything, slightly better than BMR multiples (average gradient +0.42 ) at correcting for body weight.

Fig. 1. Energy expenditure (EE), measured by Oxylog and expressed as $\mathrm{kJ} / \mathrm{kg}$ min and as a multiple of the BMR, plotted against body weight for each of three programmed activities. The three activities were: (1) walking on a treadmill at $3.1 \mathrm{~km} / \mathrm{h}$ and zero slope, (2) walking in time to a metronome at $110 \mathrm{steps} / \mathrm{min}$ and (3) building a wall of $3.06 \mathrm{~m}^{2}$ with cement blocks $(150 \times 100 \times 400 \mathrm{~mm})$ weighing $7.4 \mathrm{~kg}$ each. Subjects fell into three BMI categories: (O), BMI <20; (G), $20<\mathrm{BMI}<25$; (A), BMI $>25$. Activity 1, EE $v$. body weight $r-0.33, P=0.276$; EE $\times$ BMR $v$. body weight, $r 0.33, P=0.278$. Activity 2 , EE $v$. body weight $r-0.38, P=0.199 ; \mathrm{EE} \times \mathrm{BMR} v$, body weight $r 0.46$, $P=0.114$. Activity 3 , EE $v$. body weight $r-0.20, P=0.506$; $\mathrm{EE} \times \mathrm{BMR} v$. body weight $r 0.46, P=0.117$. 
BODY WEIGHT AND ENERGY EXPENDITURE

365
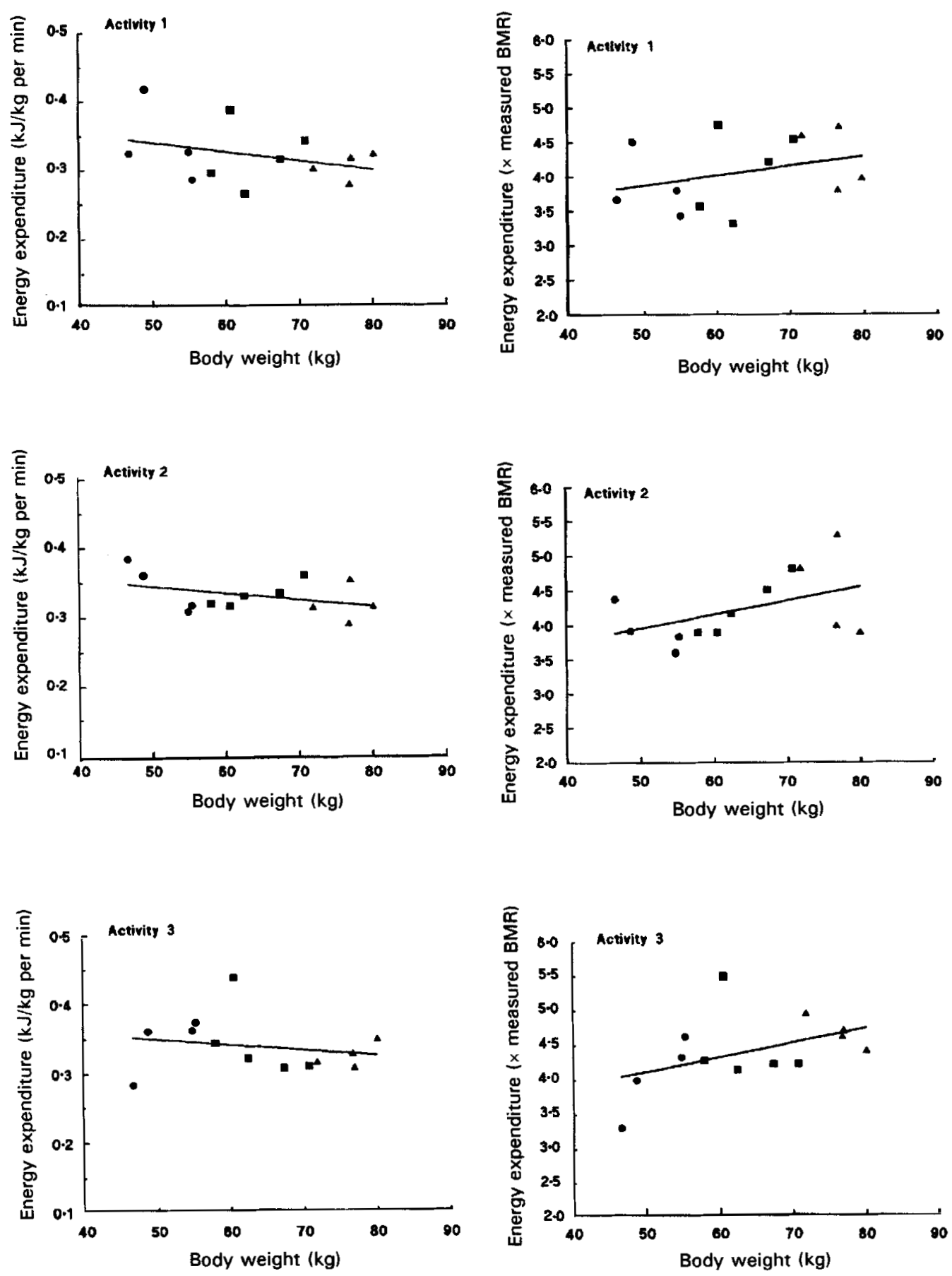
The values for the measured BMR, total, occupational and discretionary energy expenditure are given in Table 4. The measured BMR in this group was not significantly different (by paired $t$ test) from the FAO/WHO/UNU (1985) predicted values. The mean total energy expenditure was 12.68 (SE 0.73 ) $\mathrm{MJ} / \mathrm{d}$ and it is worth noting that this was not significantly different from the estimated energy intake (12.70 (SE 0.67) MJ/d), suggesting that the food intake records were representative of habitual intake. The standard error on the DLW-derived expenditure was relatively high compared with that estimated in other DLW studies in adult man where the precision has been calculated (see e.g. Coward et al. 1988; Livingstone et al. 1991; Haggarty et al. 1994a). This is partly because, with the exception of the precision reported by Haggarty et al. (1994a), the other estimates do not include error terms for the dose and background determinations and uncertainties in fractionated evaporative water loss and RQ (Haggarty et al. 1994b). Yet the standard error in the present study is also higher than that reported by Haggarty et al. (1994a) where the same approach to estimating precision was used. This is partly because the earlier study employed the two-point method of estimating $\mathrm{CO}_{2}$ production whilst the multi-point method was used here (see Coward, 1990 for a description of these approaches). The multipoint method of calculating $\mathrm{CO}_{2}$ production cannot distinguish between true daily variation in $\mathrm{CO}_{2}$ production and analytical errors; therefore, in individuals such as these, with high rates of $\mathrm{CO}_{2}$ production during work days and relatively low rates during rest days, the precision of the DLW-derived $\mathrm{CO}_{2}$ production would be greater than if the two-point method were used. Finally, the water turnover of these subjects was relatively high in relation to the rate of $\mathrm{CO}_{2}$ production, resulting in a reduction in the precision of the DLW method. Diaz et al. (1991) also observed a large coefficient of variation on $\mathrm{CO}_{2}$ production in Gambian labourers with high water turnovers, and whilst we typically use a higher ${ }^{2} \mathrm{H}$ dose than most groups to ameliorate this effect (Haggarty et al. 1994a) it cannot be removed entirely.

As expected, total energy expenditure (MJ/d) increased significantly with body weight ( $r$ 0.593, $P=0.033$ ). However, when expressed as a multiple of BMR there was no significant relationship between the total expenditure and the body weight $(r 0.129$, $P=0.674$, mean: 1.78 (SE 0.07 ) $\times$ BMR). When the energy costs of the individual activities were summed to give a value for total occupational expenditure, the increase in expenditure $(\mathrm{kJ} / \mathrm{min})$ with body weight was highly significant $(P<0.001)$ and the increase in BMR multiple with body weight was also significant $(P=0.035)$. The discretionary energy expenditure was calculated as the difference between the total energy expenditure (measured using DLW) and the energy expended during occupation (measured by portable $\mathrm{O}_{2}$ analyser) and sleep (assumed to be BMR $\times 1$ ). Goldberg et al. (1988) have reported the sleeping metabolic rate of subjects in respiration chambers as $0.95 \times$ BMR. However, these authors excluded from their analysis the first half hour after putting out the chamber lights, a period during which the metabolic rate was still falling. Since the subjects in the present study were self-reporting their sleep time they would typically record the time the lights were switched off as the beginning of sleep. Also, Goldberg et al. (1988) noted that the sleeping metabolic rate was actually $1 \times$ BMR in subjects whose sleep was in some way disturbed, either because they were wearing heart-rate monitors or because of other types of discomfort experienced, for example, by obese and pregnant subjects. Since the subjects studied here were sleeping at home, many with their partners, and would be subject to the normal occasional disturbances of sleep (e.g. noisy traffic, neighbours and small children) not normally experienced in respiration chambers, we considered that $1 \times$ BMR would be a more realistic approximation for sleeping energy expenditure. 
Table 4. Daily energy expenditure by subjects doing heavy physical work, and its components

\begin{tabular}{|c|c|c|c|c|c|c|c|c|}
\hline \multirow[b]{2}{*}{ Subject } & \multirow{2}{*}{$\begin{array}{c}\text { BMR } \\
(\mathrm{MJ} / \mathrm{d})\end{array}$} & \multicolumn{3}{|c|}{$\begin{array}{l}\text { Total energy } \\
\text { expenditure }\end{array}$} & \multicolumn{2}{|c|}{$\begin{array}{c}\text { Occupational } \\
\text { energy expenditure }\end{array}$} & \multicolumn{2}{|c|}{$\begin{array}{c}\text { Discretionary } \\
\text { energy expenditure }\end{array}$} \\
\hline & & $(\mathrm{MJ} / \mathrm{d})$ & $\mathrm{SE}(\mathrm{MJ} / \mathrm{d})$ & $(\times \mathrm{BMR})$ & $(\mathrm{MJ} / \mathrm{d})$ & $(\times \mathrm{BMR})$ & $(\mathrm{MJ} / \mathrm{d})$ & $(\times \mathrm{BMR})$ \\
\hline 1 & 6.43 & 11.62 & 1.98 & 1.81 & 5.09 & 3.40 & 3.79 & 1.73 \\
\hline 2 & 5.86 & 9.63 & 0.79 & 1.64 & 3.97 & $3 \cdot 13$ & 3.54 & 1.43 \\
\hline 3 & 6.69 & 13.87 & 2.25 & 2.07 & 5.04 & 3.23 & 6.52 & 2.32 \\
\hline 4 & 6.53 & 13.18 & $2 \cdot 12$ & 2.02 & 4.98 & 3.27 & 5.97 & $2 \cdot 15$ \\
\hline 5 & 7.02 & 10.92 & 3.55 & 1.56 & 6.29 & 3.84 & 1.97 & 0.73 \\
\hline 6 & 6.80 & 10.50 & 2.85 & 1.55 & 5.13 & 3.24 & 2.96 & 1.06 \\
\hline 7 & 7.09 & $11 \cdot 15$ & 2.70 & 1.57 & 5.30 & 3.21 & 2.89 & 1.17 \\
\hline 8 & 7.58 & $14 \cdot 30$ & 1.89 & 1.89 & 6.54 & 3.70 & 5.42 & 1.56 \\
\hline 9 & $7 \cdot 15$ & 11.72 & 5.46 & 1.64 & 5.91 & 3.54 & $3 \cdot 31$ & 1.11 \\
\hline 10 & 7.94 & $15 \cdot 54$ & 1.71 & 1.96 & 6.30 & 3.40 & 6.42 & 1.96 \\
\hline 11 & 6.69 & 10.26 & 1.86 & 1.53 & 6.07 & 3.89 & 1.43 & 0.60 \\
\hline 12 & $7 \cdot 33$ & $15 \cdot 21$ & 2.41 & 2.08 & 6.81 & 3.98 & $6 \cdot 30$ & 1.79 \\
\hline 13 & 9.22 & 16.94 & 2.41 & 1.84 & 7.26 & 3.38 & $6 \cdot 34$ & 1.70 \\
\hline Mean & $7 \cdot 10$ & 12.68 & 2.46 & 1.78 & 5.75 & 3.48 & $4 \cdot 37$ & 1.49 \\
\hline$S E$ & 0.26 & 0.73 & 0.31 & 0.07 & 0.29 & 0.09 & 0.58 & 0.17 \\
\hline \multicolumn{9}{|c|}{ Correlation with body weight } \\
\hline$r$ & 0.872 & 0.593 & - & 0.129 & 0.923 & 0.586 & 0.154 & -0.0769 \\
\hline$P$ & $<0.001$ & 0.033 & - & 0.674 & $<0.001$ & 0.035 & 0.616 & 0.803 \\
\hline
\end{tabular}

The mean discretionary energy expenditure was 4.37 (SE 0.58 ) $\mathrm{MJ} / \mathrm{d}$ or 1.49 (SE $0.17) \times$ BMR. It can be seen from Table 4 that the average multiple of BMR during discretionary time was below 1 in two of the subjects. However, this was not due to an extraordinarily low level of expenditure; the lower-than-expected value arises because of the variability in the DLW-derived value for expenditure which is used to calculate discretionary expenditure. Whilst there was a small increase in discretionary expenditure with increasing body weight this effect was not significant.

The observation of increasing BMR multiple with increasing body weight can also be seen in theoretical calculations based on published equations relating the energy cost of a given activity to the body weight (see e.g. Margaria et al. 1963; Spurr, 1988). Calculation of the BMR, from the FAO/WHO/UNU (1985) equations, and the energy cost of an activity from such empirically derived equations enables us to estimate the expected BMR multiple for each activity across a wide range of body weights. Such calculations are most useful if they are based on commonly performed activities relevant to a substantial proportion of the population. Manual transportation of loads in developing countries persists as a major occupation of the adult workforce and Spurr (1988) has presented empirically derived equations for the energy cost of walking in well-nourished and undernourished subjects across a wide range of ages (6-37 years) and body weights (20$80 \mathrm{~kg}$ ) whilst walking with and without loads. Leisure activities such as jogging may also make an important contribution to total energy expenditure, particularly in developed countries (Haggarty et al. 1994b), and for this activity the empirically derived equations of Margaria et al. (1963) are probably the most appropriate. Calculations based on these equations are presented in Fig. 2. It can be seen from Fig. 2(a) that, for the activities chosen, the BMR multiple was not constant across a range of body weights but increased in a hyperbolic manner as weight increased, with the largest effect at the highest levels of expenditure. Because of the hyperbolic form of the relationship the effect on the BMR multiple of reducing body weight by $30 \mathrm{~kg}$ from $70 \mathrm{~kg}$ to $40 \mathrm{~kg}$ is greater than increas- 
(a)
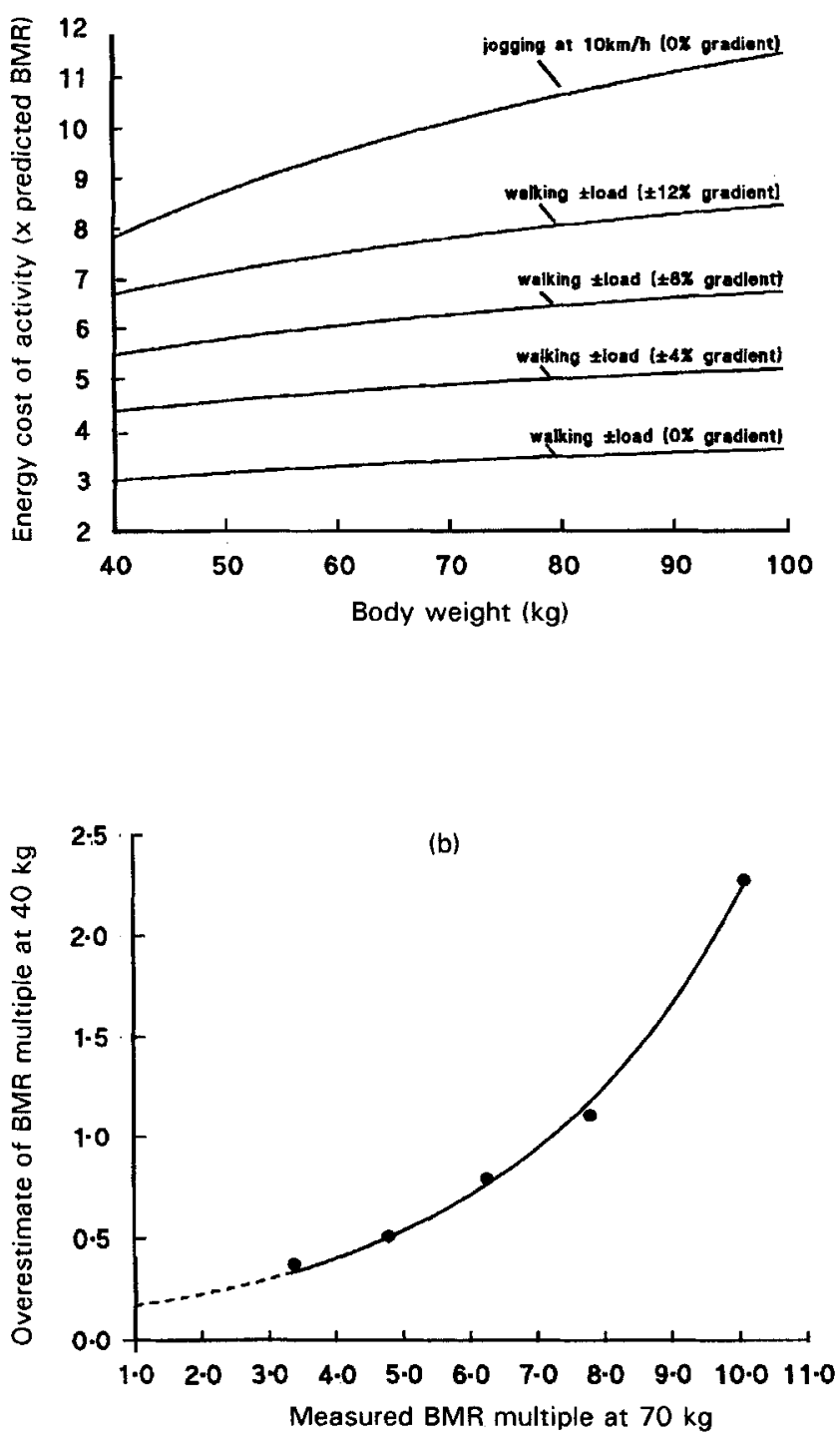

Fig. 2. (a) BMR was predicted from the body weight (W) in $\mathrm{kg}$ using the Food and Agriculture Organization/World Health Organization/United Nations University (1985) prediction equation for males in the age range 18-30 years $(B M R(M J / d)=0.064 \mathrm{~W}+2.84$ or $B M R(\mathrm{~kJ} / \mathrm{min})=0.044 \mathrm{~W}+1.972)$. The energy cost of individual activities (expressed as a multiple of the BMR) was calculated by estimating the energy cost from body weight using published equations and dividing this by the predicted BMR. The energy cost of walking $(\mathrm{kJ} / \mathrm{min})$ with and without loads was calculated using the empirically derived equations of Spurr (1988) at $0 \%$ gradient $(0.197 \mathrm{~W}+3.36)$, $\pm 4 \%$ gradient $(0.280 \mathrm{~W}+5.15), \pm 8 \%$ gradient $(0.377 \mathrm{~W}+5.40), \pm 12 \%$ gradient $(0.485 \mathrm{~W}+5.65)$ and the energy cost of jogging at $10 \mathrm{~km} / \mathrm{h}$ estimated using the value of $4.4 \mathrm{~kJ} / \mathrm{kg}$ per $\mathrm{km}$ obtained by Margaria et al. (1963) in untrained individuals. (b) Figure derived from the data presented in (a) by calculating the predicted BMR multiple at $70 \mathrm{~kg}$ and $40 \mathrm{~kg}$ body weight for each of the five activities. The overestimate of the BMR multiple at $40 \mathrm{~kg}$ resulting from the assumption that it is the same as the $70 \mathrm{~kg}$ value was calculated and plotted against the BMR multiple at $70 \mathrm{~kg}$. An exponential was then fitted to the five data points yielding an equation describing the error at $40 \mathrm{~kg}$ body weight as equal to $0.131 \exp ^{0.282} \times$ BMR nnultiple at $70 \mathrm{~kg}$. 
ing it by $30 \mathrm{~kg}$ from $70 \mathrm{~kg}$ to $100 \mathrm{~kg}$. The increase in the magnitude of this effect with increasing level of expenditure is most clearly seen in Fig. 2(b) where the overestimate of the BMR multiple at $40 \mathrm{~kg}$ is plotted against the measured BMR multiple at $70 \mathrm{~kg}$. The error at $40 \mathrm{~kg}$ not only increases with the level of expenditure but it apparently does so in an exponential fashion with the error being approximately equal to $0.131 \exp ^{0.282} \times \mathrm{BMR}^{2}$ multiple at $70 \mathrm{~kg}$. Thus, for walking on the level or at shallow gradients $( \pm 4 \%$ ) the energy cost of this activity would apparently be overestimated by $0.4 \times$ BMR on extrapolating from $70 \mathrm{~kg}$ to $40 \mathrm{~kg}$. The effect at steeper gradients $( \pm 8 \%$ to $\pm 12 \%)$ would be about $1 \times \mathrm{BMR}$, whilst for more strenuous activities such as jogging the overestimate would be approximately $2.3 \times$ BMR. These effects do not, of course, signify a real increase in energetic efficiency at lower body weights but simply highlight the potential errors introduced by the BMR multiple approach, at least for the activities studied here.

\section{DISCUSSION}

Shetty \& James (1994) have argued that the published data support the proposition that adults with low BMI are forced to adapt their behaviour in terms of spontaneous, freeliving physical activity. Such an effect should be reflected in a greater-than-expected fall in the energy expended during discretionary activity with decreasing-body weight. Although Shetty \& James (1994) were primarily concerned with chronic energy deficiency and therefore very low BMI $\left(<18.5 \mathrm{~kg} / \mathrm{m}^{2}\right)$ this effect has also been reported in subjects within the 'normal' BMI range (Torun et al. 1989). Torun et al. (1989) found that agricultural workers in Guatemala with a relatively low BMI (mean $20.1 \mathrm{~kg} / \mathrm{m}^{2}$ ) spent much of their discretionary time in sedentary activities or sleeping after performing a standardized set of agricultural tasks, whilst the higher BMI group (mean $23.2 \mathrm{~kg} / \mathrm{m}^{2}$ ) did not sleep during the day and took part in higher intensity activities such as soccer during discretionary time. The results presented here indicate no significant correlation between body weight (or BMI) and the time spent in sleep. Neither was there a decrease in the BMR multiple or the absolute rate of expenditure during discretionary time with decreasing body weight. Indeed, there was a slight increase in the BMR multiple with decreasing body weight and BMI. This suggests that the behavioural 'adaptation' observed by Torun et al. (1989) would appear to be due to chronic energy deficiency per se rather than reduced body weight.

Metabolic or non-behavioural 'adaptation' should be apparent in an increase in the energetic efficiency associated with one or both of the main components of energy expenditure; the BMR and the energy cost of activities. The measured BMR values presented here were not significantly different from those predicted from the body weight on the basis of the equations presented in the FAO/WHO/UNU (1985) report. However, the results for the energy costs of activities indicated that the BMR multiple associated with programmed occupational activities, such as walking and building a wall, increased with body weight. Whilst these trends were not statistically significant for the individual activities, when summed to give a value for total occupational expenditure the resulting increase in BMR multiple with body weight gave a $P$ value of 0.035 . Furthermore, theoretical calculations based on empirically derived equations for the BMR and energy costs of common activities support the conclusion that the BMR multiple associated with activities increases with increasing body weight. One of the main reasons for using the BMR-multiple approach to calculate energy requirements is that it is supposed to compensate for differences in body weight between individuals. However, the 
experimental results and theoretical calculations presented here suggest that this assumption may need to be re-examined. The BMR-multiple approach has been used in both the FAO/WHO/UNU (1985) report and, more recently by the Department of Health (1991) in the UK to estimate energy requirements and it is often used in the literature to express energy expenditure as a 'physical activity level' or 'physical activity ratio' (see e.g. James \& Schofield, 1990). The BMR-multiple approach has the great advantage that it is easy to understand and simple to use but its validity across a wide range of body weights has apparently not previously been tested. Indeed it is frankly stated in the FAO/WHO/UNU (1985) document, where this method first appeared, that "In the absence of data it has been assumed in this report that, regardless of body weight, the same multiple of BMR can be used to express the energy cost of each activity". The theoretical basis for this assumption is not given in the report but we can deduce the pre-requisites for its validity. The energy cost of an activity, expressed as a multiple of the BMR is calculated as:

$$
\text { BMR multiple }=\frac{\text { energy cost of activity (energy/time) }}{\text { BMR(energy/time) }} .
$$

Both the energy cost of activities and the BMR are typically expressed as linear functions of the body weight (see e.g. Margaria et al. 1963; FAO/WHO/UNU, 1985; Spurr, 1988), therefore the equation can be rewritten as:

$$
\text { BMR multiple }=\frac{\text { gradient }_{\text {activity }} \cdot \text { body weight }+ \text { intercept }_{\text {activity }}}{\text { gradient }_{B M R} \cdot \text { body weight }+ \text { intercept }_{B M R}} .
$$

For an equation of this form, the only circumstance in which the BMR multiple will be a constant for different body weights is when the ratio of the gradients equals the ratio of the intercepts, i.e.:

$$
\frac{\text { gradient }_{\text {activity }}}{\text { gradient }_{B M R}}=\frac{\text { intercept }_{\text {activity }}}{\text { intercept }_{B M R}} .
$$

There have been many attempts at functional interpretations of empirical relationships between the components of energy expenditure and the body weight but we know of no underlying physiological reason why the ratios of the gradients and intercepts for the energy costs of activities and the BMR should be equal. Indeed the calculations presented here indicate that the BMR multiple not only varies with body weight but it increases in a hyperbolic manner, with the rate of increase being highest for the most strenuous activities. However, the important question is whether the magnitude of the errors arising from the simplifying assumption of a constant BMR multiple outweigh the convenience of this approach.

If the BMR multiple associated with an activity is measured directly in a group at the same body weight as those in whom it is to be used then no error will arise. However, if for example the energy cost of activity was measured in a $70 \mathrm{~kg}$ subject and the resulting BMR multiple applied to a $40 \mathrm{~kg}$ subject there would be an overestimate of energy expenditure. The resulting error would always be of the same sign and therefore additive for each activity. In an analogous fashion, BMR multiples derived in low-body-weight individuals would result in an underestimate of energy expenditure if applied to individuals of higher body weight. Using the relationship between the overestimate of energy expenditure at $40 \mathrm{~kg}$ and the BMR multiple at $70 \mathrm{~kg}$ derived here for a range of activities, we can estimate the typical error on each of the examples given in the FAO/WHO/UNU (1985) report by 
calculating how much each BMR multiple would be overestimated in a $40 \mathrm{~kg}$ subject after extrapolation from measurement in a $70 \mathrm{~kg}$ subject. Assuming that the BMR is not in error, we calculate that energy expenditure would be overestimated by about $10 \%$ for each of the three examples of 'light', 'moderate' and 'heavy' work for adult males. Thus, if the assumed constancy of the BMR multiple were wrong, in the manner described, then we would expect to find significant discrepancies between the measured expenditure and that predicted by FAO/WHO/UNU (1985). Furthermore, such an error might be interpreted as 'adaptation' if direct measurements in low-body-weight subjects were compared with the FAO/WHO/UNU (1985) estimates. It is therefore important to be aware of the potential for bias introduced by the use of BMR multiples, particularly when addressing the issue of metabolic 'adaptation'.

Assuming that the BMR multiples used in the report were derived in subjects of similar body weight to those described here (mean $64 \mathrm{~kg}$ ), it is useful to compare the mean value for total energy expenditure with that predicted by FAO/WHO/UNU (1985). The total energy expenditure of these construction workers performing 'heavy' work was $1.78 \times$ BMR. This value is consistent with the recent Department of Health (1991) guidelines for adult males with occupations in the highest expenditure category (1.7$1.9 \times$ BMR depending on the level of non-occupational activity) but a good deal lower than the FAO/WHO/UNU (1985) estimate of $2.10 \times$ BMR for men engaged in 'heavy' work. Indeed, the measured value of $1.78 \times \mathrm{BMR}$ corresponds exactly to that given in the FAO/WHO/UNU (1985) report for adult males engaged in only 'moderate' work. Assuming that the results presented here are correct, this discrepancy must be due to an overestimate in the report of the energy cost of 'heavy' work and/or an overestimate of the time typically spent in 'heavy' work. In the sample calculation given in the report it is assumed that 'heavy' work is performed at $3.8 \times$ BMR and that discretionary activity is approximately $1.76 \times$ BMR. In the subjects described here the measured occupational expenditure was 3.4 (SE 0.09) $\times$ BMR and the discretionary expenditure, calculated by subtracting the expenditure in sleep and occupation from total energy expenditure, was 1.5 (SE 0.17) $\times$ BMR. These relatively small differences in the BMR multiples used explain about $40 \%$ of the discrepancy between the FAO/WHO/UNU (1985) report and the direct measurements presented here. The main reason for the discrepancy lies in the assumption of the amount of time spent in occupation. The exact values used to calculate the expected BMR multiples of 1.78 and 2.10 are not given in the FAO/WHO/UNU (1985) report but the sample calculations which result in the same BMR multiples do provide full details of the assumed time allocation and their associated energy costs. It would appear from these calculations that the final BMR multiples have been estimated assuming that occupation is carried out for $8 \mathrm{~h} / \mathrm{d}$, every day, although it is acknowledged elsewhere in the report that occupational time has to be averaged over a typical week. Thus for example the $8 \mathrm{~h}$ working day, $5 \mathrm{~d}$ week typical of most developed countries would result in an average of $5.7 \mathrm{~h} / \mathrm{d}$ spent in occupation. This corresponds well to the average of $5.6 \mathrm{~h} / \mathrm{d}$ of programmed occupation carried out in the present study (the slightly lower value in this study is due to the inclusion of a $1 \mathrm{~h}$ lunch break within the working day). An assumption may have been made in the report that an $8 \mathrm{~h}$ working day, without a weekend break, is the prevailing pattern in developing countries but it is important to be aware of this assumption if the FAO/WHO/UNU (1985) estimates are to be applied to groups such as those studied here whose work patterns are more typical of developed countries.

Although the proposals of Sukhatme \& Margen (1982) have become synonymous with 'adaptation' to chronic energy deficiency in developing countries, their hypothesis is based on an analysis of measurements made by other workers in well-nourished subjects, mainly 
in the UK and USA. Their argument seems to be that the observed variability in energy intake between individuals whilst in approximate energy balance is in fact largely due to variation over time within an individual. In inferring from the data available to them that the level of physical activity is relatively constant within an individual, Sukhatme \& Margen (1982) considered it necessary to invoke some energy dissipating mechanism other than physical activity to account for the changes in energy expenditure necessary to achieve energy balance; one suggestion being that utilization of metabolic pathways with greater or lesser inherent energetic efficiency could provide the necessary 'flexibility' by increasing expenditure when intake is high and decreasing it when intake is low. In essence this hypothesis is indistinguishable from 'luxuskonsumption' which was first proposed at the beginning of the century (Neumann, 1902; Gulick, 1922). With the advent of techniques such as the DLW method it is now possible to verify the inferences and assumptions underlying such hypotheses. Sukhatme \& Margen's (1982) assumption that the observed coefficient of variation (CV) in food intake within individuals of about $16 \%$ is largely a reflection of temporal variability within individuals is partly supported by our own observations on the magnitude of seasonal changes in energy expenditure (CV $18 \%$ ) as measured by DLW (Haggarty et al. 1994b). However, some of the subjects in that study were much more active than the general population, therefore we would expect a lower $\mathrm{CV}$ in the population as a whole. Furthermore, contrary to Sukhatme \& Margen's (1982) assumption, the between-subject variability in this group was actually greater (CV $22 \%$ ) than the within-subject effect. More importantly, the assumption that similar activity patterns imply similar levels of expenditure is not supported by the results presented here and our previous studies (Haggarty et al. 1994b) which indicate that, depending on factors such as the overall level of fitness, there can be large differences in the level of expenditure associated with a given activity.

Not only can the BMR multiple associated with an activity vary over a wide range (particularly for the higher expenditure activities) depending on how regularly that activity is carried out (Haggarty et al. 1994b), but the data presented here suggest that the BMR multiple may also vary with the body weight and that this should be taken into account when using this approach to estimate energy requirements, particularly at the extremes of body weight. If this is not done there would appear to be more evidence that errors introduced by the use of the BMR-multiple approach at low body weights will produce a spurious case for metabolic 'adaptation' than there is experimental evidence for the phenomenon itself.

The authors would like to thank the International Atomic Energy Authority, The Scottish Office Agriculture and Fisheries Department, and the Commission of the European Communities who provided financial support for this work.

\section{REFERENCES}

Benedict, F. G., Miles, W. R., Roth, P. \& Smith, H. M. (1919). Human Vitality and Efficiency under Prolonged Restricted Diet. Publication no. 280. Washington, DC: Carnegie Institute.

Black, A. E., Prentice, A. M. \& Coward, W. A. (1986). Use of food quotients to predict respiratory quotients for the doubly labelled water method of measuring energy expenditure. Human Nutrition: Clinical Nutrition 40C, 381-391.

Coward, W. A. (1990). Calculation of pool size and flux rates. In IDECG Report. The Doubly Labelled Water Method for Measuring Energy Expenditure. Technical Recommendations for Use in Humans, pp. 114-146 [A. M. Prentice, editor]. Vienna: International Atomic Energy Agency.

Coward, W. A., Roberts, S. B. \& Cole, T. J. (1988). Theoretical and practical considerations in the doubly labelled water $\left({ }^{2} \mathrm{H}_{2}{ }^{18} \mathrm{O}\right)$ method for measurement of carbon dioxide production rate in man. European Journal of Clinical Nutrition 42, 207-212. 
Department of Health (1991). Dietary Reference Values for Food Energy and Nutrients for the United Kingdom. Report on Health and Sacial Subjects no. 41. London: H. M. Stationery Office.

Diaz, E., Goldberg, G. R., Taylor, M., Savage, J. M., Sellen, D., Coward, W. A. \& Prentice, A. M. (1991). Effects of dietary supplementation on work performance in Gambian laborers. American Journal of Clinical Nutrition 53, 803-811.

Food and Agricultural Organization/World Health Organization/United Nations University (1985). Energy and Protein Requirements. Report of a Joint Expert Consultation. WHO Technical Report Series, no. 724. Geneva: WHO.

Goldberg, G. R., Prentice, A. M., Davies, H. L. \& Murgatroyd, P. R. (1988). Overnight and basal metabolic rates in men and women. European Journal of Clinical Nutrition 42, 137-144.

Grijalva, M. I., Caire, G., Sanchez, A. \& Valencia, M. E. (1995). Chemical composition, dietary fiber and mineral content of frequently consumed foods in Northwest Mexico. Archivos Latinoamericanos de Nutricion $45,145-150$.

Gulick, A. (1922). A study of weight regulation in the adult human body during over-nutrition. American Journal of Physiology 60, 371-395.

Haggarty, P., Franklin, M. F., Fuller, M. F., MacGaw, B. A., Christie, S. L., Milne, E., Duncan, G. \& Smith, J. S. (1994a). Validation of the doubly labelled water method in growing pigs. American Journal of Physiology 267, R1574-R1588.

Haggarty, P., McNeill, G., Abu Manneh, M. K., Davidson, L., Milne, E., Duncan, G. \& Ashton, J. (1994b). The influence of exercise on the energy requirements of adult males in the UK. British Journal of Nutrition, 72 , 799-813.

Hernandez, M., Chavez, A. \& Bourges, H. (1980). The Nutritive Value of Foods, 8th ed. Mexico DF, Mexico: Instituto Nacional de la Nutricion.

Humphrey, S. J. E. \& Wolf, H. S. (1977). The Oxylog. Journal of Physiology 12P, 267.

James, W. P. T. (1988). Research relating to energy adaptation in man. In Chronic Energy Deficiency: Consequences and Related Issues, pp. 7-36 [B. Schurch and N. S. Scrimshaw, editors]. Lausanne: International Dietary Energy Consultancy Group.

James, W. P. T. \& Schofield, E. C. (1990). Human Energy Requirements. Oxford: Oxford University Press.

Jardines, R. P., Bermudez, M. C., Wong, P. \& Leon, G. (1985). Dishes (or: "mixed meals") consumed in Sonora: regionalization and nutrient content. Archivos Latinoamericanos de Nutricion 37, 785-789.

Keys, A., Brozek, A., Henschel, A., Miccelsen, O. \& Taylor, H. L. (1950). The Biology of Human Starvation. Minneapolis: University of Minnesota Press.

Livingstone, M. B. E., Strain, J. J., Prentice, A. M., Coward, W. A., Nevin, G. B., Barker, M. E., Hickey, R. J., McKenna, P. G. \& Whitehead, R. G. (1991). Potential contribution of leisure activity to the energy expenditure patterns of sedentary populations. British Journal of Nutrition 65, 145-155.

McNeill, G., Cox, M. D. \& Rivers, J. P. W. (1987). The Oxylog oxygen consumption meter: a portable device for measurement of energy expenditure. American Journal of Clinical Nutrition 45, 1416-1419.

Margaria, R., Cerretelli, P., Aghemo, P. \& Sassi, G. (1963). Energy cost of running. Journal of Applied Physiology 18, 367-370.

Neumann, R. O. (1902). Experimentelle Beitrage zur Lehre von dem taglichen Nahrungsbedarf des Menschen unter besonder Berucksichtigung der notwendigen Eiweissmenge (Experiments relating to the study of the daily nutritional requirements in man with particular consideration of the required amounts of protein). Archives für Hygeine und Bacteriologie 45, 1-87.

Paul, A. A. \& Southgate, D. A. T. (1985). McCance and Widdowson's The Composition of Foods, 3rd ed. London: Elsevier.

Shetty, P. S. \& James, W. P. T. (1994). Body Mass Index, a Measure of Chronic Energy Deficiency in Adults. Food and Agriculture Organization Food and Nutrition Paper 56. Rome: FAO.

Spurr, G. B. (1988). Effects of chronic energy deficiency on stature, work capacity and productivity. In Chronic Energy Deficiency: Consequences and Related Issues, pp. 95-134 [B. Schurch and N. S. Scrimshaw, editors]. Lausanne: International Dietary Energy Consultancy Group.

Sukhatme, P. V. \& Margen, S. (1982). Auto-regulatory homeostatic nature of energy balance. American Journal of Clinical Nutrition 35, 355-365.

Torun, B., Flores, R., Viteri, F., Immink, M. \& Diaz, E. (1989). Energy supplementation and work performance: Summary of Incap studies. Proceedings of the XIV International Congress of Nutrition, Seoul, pp. 306-309. Seoul: Korean Nutrition Society.

U.S. Department of Agriculture (1986). Handbook of the Nutritional Value of Foods in Common Units. Prepared by Catherine F. Adams for the US Department of Agriculture. New York: Dover Publications, Inc.

Weir, J. B. De V. (1949). New methods of calculating metabolic rate, with special reference to protein metabolism. Journal of Physiology 109, 1-9. 